\title{
Ocorrência de anticorpos anti-Neospora spp. em jumentos (Equus asinus) no estado de Sucre - Colômbia
}

\author{
[Occurrence of anti-Neospora spp. Antibodies in donkeys (Equus asinus) \\ in the state of Sucre - Colombia] \\ R.D. Blanco ${ }^{1}$, J.H. Patarroyo, ${ }^{2}$, M.I. Vargas $^{2}$, J.A. Cardona ${ }^{3,4}$, \\ L.S. Araújo ${ }^{1}$, V.E. Gomez ${ }^{1,4}$ \\ ${ }^{1}$ Aluno de pós-graduação - Universidade Federal de Viçosa -Viçosa, MG \\ ${ }^{2}$ Universidade Federal de Viçosa - Viçosa, MG \\ ${ }^{3}$ Universidade de Córdoba - Faculdade de Medicina Veterinária - Montería, Colômbia \\ ${ }^{4}$ Bolsista do Programa Estudantes-Convênio de Pós-Graduação - PEC-PG, da Capes/CNPq - Brasil

\section{RESUMO}

A neosporose tem grande importância em bovinos, e sua patogênese neste hospedeiro, em termos gerais, está esclarecida, porém, em equídeos é pobremente conhecida. Na Colômbia ainda não foram reportados anticorpos Anti-Neospora spp. em equídeos, sendo assim objetivou-se no presente estudo avaliar a ocorrência do parasito em jumentos (Equus asinus) de fazendas que apresentavam risco da doença nestes animais. Foram utilizados 56 animais no estado de Sucre (Colômbia), escolhidos aleatoriamente dentro das fazendas selecionadas. Utilizou-se um peptídeo recombinante originado de Neospora caninum (NcGRA1) para o diagnóstico por Dot-ELISA, e o soro foi diluído em 1:200. Este estudo reporta, pela primeira vez no estado de Sucre e na Colômbia, a presença de anticorpos anti-Neospora spp. na espécie Equus asinus, com uma ocorrência de 19,7\% (11/56) dos animais amostrados.

Palavras-chave: jumento (Equus asinus), ocorrência, Neospora spp., parasito

\begin{abstract}
The neosporosis has great importance in cattle, and its pathogenesis in this host has been generally clarified, however, in horses, neosporosis is poorly known, and in Colombia anti-Neospora spp antibodies have not been reported. Therefore, the main objective in the present study was to evaluate the occurrence of this parasite in donkeys (Equus asinus) from farms that presented a risk of disease in these animals, as well as no health plan for them. Were used 56 animals randomly chosen inside selected farms in the state of Sucre (Colombia). A recombinant peptide originated from Neospora caninum (NcGRA1) was used for the diagnosis with Dot-ELISA and serum was diluted 1:200. This study is the first to report the presence of anti-Neospora spp. in donkeys (Equus asinus) in the state of Sucre, and in Colombia. The occurrence was in $19.7 \%$ of the animals sampled (11/56).
\end{abstract}

Keywords: donkey (Equus asinus), occurrence, Neospora spp., parasite

\section{INTRODUÇÃO}

A neosporose é uma doença que acomete bovinos, cães, ovinos, caprinos, cervos, búfalos e equinos (Locatelli-Dittrich et al., 2006). O protozoário do gênero Neospora pertence ao filo Apicomplexa, classe Sporozoea, ordem Eucoccidiida e família Sarcocystidae. No gênero
Neospora, duas espécies são conhecidas, Neospora caninum e Neospora hughesi (Dubey et al., 2002), sendo que a infecção por $N$. caninum tem sido associada a problemas reprodutivos e à doença neonatal, e a infecção por $N$. hughesi a distúrbios neurológicos (Veronesi et al., 2008).

Recebido em 3 de julho de 2013 
$N$. caninum tem os cães e os coiotes como hospedeiros definitivos (Gondim et al., 2004) e várias espécies como hospedeiros intermediários (Gondim, 2006). O hospedeiro definitivo de $N$. hughesi, por sua vez, ainda é desconhecido, permanecendo incerta a forma de exposição dos cavalos a este parasita, além da possibilidade de outros hospedeiros intermediários (Hoane et al., 2006).

A infecção por $N$. caninum pode ocorrer tanto pela via horizontal, por meio da ingestão de oocistos excretados pelo hospedeiro definitivo, como pela via vertical, transplacentária (Dubey, 1999). Porém, em equinos, apesar da suspeita da infecção pela segunda via (Toscan et al., 2010), somente recentemente foi comprovada para $N$. hughesi (Pusterla et al., 2011).

A neosporose foi diagnosticada em cavalos adultos com sinais clínicos semelhantes aos da mieloencefalite protozoária equina - MPE (Dubey et al., 2001), sendo os sinais clínicos característicos da enfermidade em equinos cegueira, paralisia dos membros pélvicos, distúrbios comportamentais, dificuldade de mastigação, incoordenação, ataxia, doenças viscerais, doença neonatal, aborto e perda de peso (Walsh et al., 2000).

Os métodos sorológicos e parasitológicos são utilizados no diagnóstico da neosporose. Os testes sorológicos são a reação de imunofluorescência indireta (RIFI), ensaio imunoenzimático (ELISA), soroaglutinação direta e Western blotting. Entre os métodos parasitológicos estão os exames histopatológico, imuno-histoquímico, o isolamento in vitro e in vivo e a detecção do DNA do parasita pela reação em cadeia da polimerase - PCR (Hoane et al., 2006).

Na América do Sul, N. hughesi ainda não foi isolado, e na maioria dos estudos de soroprevalência e de diagnóstico sorológico, são utilizados os taquizoítos de $N$. caninum como antígeno, não sendo possível, portanto, a diferenciação da espécie de Neospora detectada por estes métodos devido à existência de reação cruzada (Patitucci et al., 2004).

Tendo em vista a escassez de dados da infecção por Neospora spp. na Colômbia, este estudo visou avaliar a ocorrência de anticorpos anti-
Neospora spp. em jumentos (Equus asinus) no estado de Sucre - Colômbia.

\section{MATERIAL E MÉTODOS}

O estudo foi realizado no estado de Sucre, Colômbia, com localização entre as coordenadas $9^{\circ} 14^{\prime} 45^{\prime \prime}$ de latitude norte e $75^{\circ} 08^{\prime} 58^{\prime \prime}$ de longitude oeste do meridiano de Greenwich, a uma altitude de 125 m.s.n.m, com temperatura média anual de $28^{\circ} \mathrm{C}$, umidade relativa de $75 \%$, precipitação média anual de $1100 \mathrm{~mm}$ e pertencente à formação climática de bosque tropical chuvoso. A região apresenta duas estações bem definidas, chuvosa e seca (Pabón $e t$ al., 2001).

No presente estudo, foram coletadas aleatoriamente amostras de 56 jumentos (Equus asinus), em várias propriedades pecuárias no estado de Sucre, escolhidas por apresentarem possíveis riscos de doenças pela presença de cachorros e apresentação de abortos em diferentes espécies, além do pouco controle sanitário para a espécie estudada. Foram coletadas amostras de 48 jumentos machos e oito fêmeas, os quais apresentavam idades entre 1,6 e 21 anos, avaliando-se, assim, ambos os sexos e diferentes idades.

Para a coleta das amostras, cada animal foi imobilizado de acordo com as normas técnicas de manejo e sujeição de animais, dentro do cumprimento da Declaração Universal dos Direitos dos Animais, referente aos princípios éticos internacionais para a pesquisa biomédica com animais do Cimos (Council for International Organizations of Medical Sciences), estabelecida pela Unesco (United Cátions Educational, Scientific and Cultural Organization) e a OMS (Organización Mundial da Saúde) em 1949, e da Lei 84, de 27 de outubro de 1989 (Estatuto Colombiano de Protección Animal) (Mrad, 2006).

No laboratório clínico da Faculdade de Medicina Veterinária e Zootecnia da Universidade de Córdoba, Colômbia, o sangue foi centrifugado e os soros mantidos a $-20^{\circ} \mathrm{C}$ até serem liofilizados, para transporte ao Laboratório de Biologia e Controle de Hematozoários e Vetores (Bioagro) da Universidade Federal de Viçosa para sua posterior análise. 
Para a análise dos soros, utilizou-se um peptídeo recombinante (NcGRA1), desenhado com base na metodologia de genética reversa de epítopos antigênicos originados de uma proteína dos grânulos densos de Neospora caninum e sintetizado pela GenScript (USA). Foi produzido por meio de processo fermentativo em leveduras Pichia pastoris KM71 no mesmo local (LBCHV/DVT/Bioagro), na Universidade Federal de Viçosa.

A técnica sorológica empregada foi o Dot-Elisa para a detecção de IgG específicos para Neospora caninum, na qual membranas de nitrocelulose de $0.22 \mu \mathrm{m}$ foram sensibilizadas com $1 \mu \mathrm{L}$ do antígeno e, posteriormente, os soros foram diluídos a 1:200 em solução de lavagem e incubados durante uma hora. A revelação foi feita mediante a adição de proteína $G$ marcada com peroxidase por 30 minutos, seguida da solução reveladora à base de 3,3'diaminobenzidine (DAB). O procedimento foi realizado em temperatura ambiente em agitação constante.

\section{RESULTADOS E DISCUSSÃO}

Dubey e Porterfield (1990) relataram o primeiro caso de neosporose em um feto equino abortado em 1985. A partir de então, a ocorrência da infecção por Neospora spp. foi descrita em equinos na América (Hoane et al., 2006), Ásia (Kligler et al., 2007) e Europa (Bartová et al., 2010).

No presente estudo, a ocorrência de anticorpos anti-Neospora spp. foi de 17,7\% (11/56), utilizando-se $\operatorname{IgG}$ anti- $N$. caninum. Partindo do princípio de que Neospora huguesi e Neopora caninum podem apresentar reação cruzada, ambas as espécies ou apenas uma delas pode ser responsável pela reação positiva.

Antígenos gerados a partir de domínios de superfície de Neospora caninum já têm sido utilizados e têm demonstrado resultados satisfatórios com soros bovinos (Pinheiro et al., 2013). O antígeno NcGRA1 usado neste estudo se origina de uma proteína dos grânulos densos presente nos estágios de pré-encistamento de $N$. caninum. A técnica de eleição, Dot-ELISA, provou ser eficiente, existindo uma concordância entre resultados obtidos pelo ELISA comercial e o Dot-ELISA em soros de bovinos com uma sensibilidade relativa e especificidade de $71 \%$ e $100 \%$, respectivamente (Ahmad et al., 2011).

Ao longo dos anos, a doença tem sido estudada e evidenciada por meio de distintos métodos de imunodiagnóstico, sendo reportada nos Estados Unidos em cinco regiões diferentes por Vardeleon et al. (2001), onde os autores coletaram sangue de 208 cavalos e encontraram $17 \%(36 / 208)$ das amostras com títulos contra Neospora spp. pelo teste de RIFI. Da mesma forma, McDole e Gay (2002), ao utilizarem o mesmo teste, reportaram 13\% (140/317) e $8 \%$ (160/426) de títulos de anticorpos positivos contra Neospora spp. em éguas com antecedentes de abortos e cavalos saudáveis, respectivamente.

Diversos estudos têm sido direcionados para detecção de anticorpos anti-Neospora spp. em equinos na América Latina. Reportaram-se, na região metropolitana de Curitiba, estado do Paraná, sul do Brasil, anticorpos em 14/97 $(14,4 \%)$ cavalos de carroceiros utilizando-se a técnica de RIFI (Villalobos et al., 2012). No Chile, a doença tinha sido reportada só em bovinos e caninos até 2004, quando Patittuci et al. (2004) reportaram evidência da infecção em equídeos, por meio de soros sanguíneos coletados de 145 equinos, analisados mediante Teste de Aglutinação para Neospora (NAT).

A infecção por Neospora spp. em cavalos tem sido reportada no mundo. Em equinos mantidos na ilha Jeju, Coreia do Sul, Gupta et al. (2002) relataram ocorrência de 2\% (4/191) de anticorpos anti-Neospora spp., pelo teste de RIFI. Na França, Pitel et al. (2003), por meio do teste de aglutinação, encontraram elevados títulos de anticorpos anti-Neospora spp., sendo que a ocorrência foi maior no grupo de éguas com antecedentes de aborto (16/54) do que naqueles dois grupos escolhidos aleatoriamente sem nenhum antecedente (8/45 e 10/76).

Em cavalos nascidos e criados na Itália, Ciaramella et al. (2004) identificaram anticorpos contra Neospora spp. em 28\% (42/150) dos cavalos pelo teste de RIFI. Da mesma forma, Jakubek et al. (2006) encontraram 9\% (39/414) de anticorpos anti-Neospora spp. em amostras de equídeos na Suécia. 
Nos últimos anos foi confirmada a presença de anticorpos anti-Neospora spp. em equinos na Arábia Saudita, onde $23(10 \%)$ amostras de sangue analisadas de 229 cavalos saudáveis apresentaram-se positivas (Abdullah e Alyousif, 2013). Na Turquia, um estudo feito em 125 equinos revelou, por meio de ELISA, reação positiva para presença de anticorpos antiNeospora spp. em 24\% (30/125) dos soros (Karatep, 2012).

\section{CONCLUSÕES}

Pela primeira vez no estado de Sucre e na Colômbia reporta-se a presença de anticorpos anti-Neospora spp. na espécie Equus asinus, com uma ocorrência de 19,7\% (11/56) dos animais amostrados, tendo entre os animais positivos tanto machos como fêmeas, assim como diferentes idades. Considerando-se a falta de informações sobre a importância de Neospora spp. na infecção em equídeos e sendo este o primeiro trabalho de reporte do parasito na espécie Equus asinus (jumento), é preciso continuar com pesquisas que ampliem os dados de ocorrência em outros estados da Colômbia, assim como a relação das consequências da presença deste agente na família Equidae.

\section{REFERÊNCIAS}

ABDULLAH, D.; ALYOUSIF, S. Seroprevalence of Neospora spp. in horses from Central Province of Saudi Arabia. Afr. J. biotechnol., v.12, p.982-985, 2013.

AHMAD, N.; JOZANI, J.; NEDA, Z. Adaptation of Dot-Elisa for Serodiagnosis of Neospora caninum Infestation in Aborted Cows. Global Vet.., v.7, p.149-152, 2011.

BARTOVÁ, E.; SEDLÁK, K.; SYROVÁ, M. et al. Neospora spp. and Toxoplasma gondii antibodies in horses in the Czech Republic. Parasitol. Res., v.107, p.783-785, 2010.

CIARAMELLA, P.; CORONA, M.; CORTESE, L. et al. Seroprevalence of Neospora spp. In assymptomatic horses in Italy. Vet. Parasitol., v.123, p.11-15, 2004.

DUBEY, J.P. Neosporosis in cattle: biology and economic impact. J. Am. Vet. Med. Assoc., v.214, p.1160-1163, 1999.
DUBEY, J.P.; BARR, B.C.; BARTA, J.R. et al. Redescription of Neospora caninum and its differentiation from related Coccidia. Int. J. Parasitol., v.32, p.929-94, 2002.

DUBEY, J.P.; LIDDEL, S.; MATTSON, D. et al. Characterization of the Oregon isolate of Neospora hughesi from a horse. J. Parasitol., v.87, p.345-353, 2001.

DUBEY, J.P.; PORTERFIELD, M.L. Neospora caninum (Apicomplexa) in an aborted equine fetus. Int. J. Parasitol., v.76, p.732-734, 1990.

GONDIM, L.F.P. Neospora caninum in wildlife. Trends Parasitol., v.22, p.247-252, 2006.

GONDIM, L.F.P.; McALLISTER, M.M.; PITT, W.C. et al. Coyotes (Canis latrans) are definitive hosts of Neospora caninum. Int. J. Parasitol., v.34, p.159-16, 2004.

GUPTA, G.D.; LAKRITZ, J.; KIM, J.H. et al. Seroprevalence of Neospora, Toxoplasma gondii and Sarcocystis neurona antibodies in horses from Jeju island, South Korea. Vet. Parasitol., v.106, p.193-201, 2002.

HOANE, J.S.; GENNARI, S.M.; DUBEY, J.P. et al. Prevalence of Sarcocystis neurona and Neospora spp. infection in horses from Brazil based on presence of serum antibodies to parasite surface antigen. Vet. Parasitol., v.136, p.155159, 2006.

JAKUBEK, E.B.; LUNDÉN, A.; UGGLA, A. Seroprevalences of Toxoplasma gondii and Neospora sp. infections in Swedish horses. Vet. Parasitol., v.138, p.194-199, 2006.

KARATEP, M. Investigation of Seroprevalence of Neospora spp. in Horses in Nigde Province (Turkey). Kafkas. Univ. Vet. Fak. Derg., v.18, p.39-42, 2012.

KLIGER, E.B.; SHKAP, V.; BANETH, G. et al. Seroprevalence of Neospora spp. among asymptomatic horses, aborted mares and horses demonstrating neurological signs in Israel. Vet. Parasitol., v.148, p.109-113, 2007.

LOCATELLI-DITTRICH, R.; HOFFMANN, D.C.S.; DITTRICH, J.R. Neosporose Equina Revisão. Arch. Vet. Sci., v.11, p.1-10, 2006. 
MCDOLE, M.G.; GAY, J.M. Seroprevalence of antibodies against Neospora caninum in diagnostic equine serum samples and their possible association with fetal loss. Vet. Parasitol., v.105, p.257- 260, 2002.

MRAD, A. Ética en la investigación con modelos animales experimentales. Alternativas y las 3 RS de Russel. Una responsabilidad y un compromiso ético que nos compete a todos. Rev. Col. Bioética., v.1, p.163-184, 2006.

PABÓN, J.; ESLAVA, J.; GÓMEZ, R. Generalidades de la distribución espacial y temporal de la temperatura del aire y de la precipitación en Colombia. Meteorol. Colomb., v.4, p.47-59, 2001.

PATITUCCI, A.N.; PÉREZ, M.J.; CÁRCAMO, C.M. et al. Presencia de anticuerpos sericos contra Neospora caninum en equinos en Chile. Arch. Med. Vet., v.36, p.203-206, 2004.

PINHEIRO, A.; BORSUK, S.; BERNE, M. et al. Expression of Neospora caninum NcSRS2 surface protein in Pichia pastoris and its application for serodiagnosis of Neospora infection. Pathogens and Global Health., v.107, p.116-121, 2013.

PITEL, P.H.; ROMAND, S.; PRONOST, S. et al. Investigation of Neospora sp. antibodies in aborted mares from Normandy, France. Vet. Parasitol., v.118, p.1-6, 2003.
PUSTERLA, N.; CONRAD, P.A.; PACKHAM, A.E. et al. Endogenous transplacental transmission of Neospora hughesi in naturally infected horses. J. Parasitol., v.97, p.281-285, 201.

TOSCAN, G.; CADORE, G.C.; PEREIRA, R.C. et al. Neosporose equina: ocorrência de anticorpos anti-Neospora spp. e associação entre status sorológico de éguas e de suas crias. Pes. Vet. Bras., v.30, p.641-645, 2010.

VARDELEON, D.; MARSH, A.E.; THORNE, J.G. et al. Prevalence of Neosporahughesi and Sarcocystis neurona antibodies in horses from various geographical locations. Vet. Parasitol., v.95, p.273- 282, 2001.

VERONESI, F.; DIAFERIA, M.; MANDARA, M.T. et al. Neospora spp. infection associated with equine abortion and/or stillbirth rate. Vet. Res. Commun., v.32, p.223-226, 2008.

VILLALOBOS, E.; FURMAN, K.; LARA, M. et al. Detection of Neospora sp. antibodies in cart horses from urban areas of Curitiba, Southern Brazil. Rev. Bras. Parasitol. Vet., v.21, p.68-70, 2002.

WALSH, C.P.; DUNCAN, R.B.; ZAJAC, A.M. et al. Neospora hughesi: Experimental infections in mice, gerbils and dogs. Vet. Parasitol., v.98, p.119-129, 2000. 